ERR A T UM

Jie Zhao $\cdot$ Hong-Yuan Yang $\cdot$ Elizabeth M. Lord

\title{
Calcium levels increase in the lily stylar transmitting tract after pollination
}

Published online: 15 January 2004

(C) Springer-Verlag 2004

\section{Sex Plant Reprod (2003)}

DOI 10.1007/s00497-003-0193-5

For this paper there are two corresponding authors, Jie Zhao and Elizabeth M. Lord.

The online version of the original article can be found at http://dx.doi.org/10.1007/s00497-003-0193-5

J. Zhao $(\bowtie) \cdot$ H.-Y. Yang

Key Laboratory of MOE for Plant Developmental Biology,

College of Life Science,

Wuhan University,

430072 Wuhan, China

e-mail: jzhao@whu.edu.cn

Tel.: +86-27-87682378

Fax: +86-27-87646010

E. M. Lord (

Department of Botany and Plant Sciences,

University of California,

Riverside, CA 92521, USA

e-mail: LORD@citrus.ucr.edu

Tel.: 9097874441

Fax: 9097874437 